Article

\title{
Distribution of Solar Radiation on Greenhouse Convex Rooftop
}

\author{
Joseph Appelbaum *(D) and Avi Aronescu \\ School of Electrical Engineering, Tel Aviv University, Tel Aviv 69978, Israel; aviarone@gmail.com \\ * Correspondence: appel@eng.tau.ac.il
}

Received: 14 July 2020; Accepted: 27 August 2020; Published: 3 September 2020

check for updates

\begin{abstract}
Photovoltaic greenhouses became popular in many countries for growing crops and, at the same time, generating electricity mainly for own usage to control the air temperature inside the greenhouse. Solar radiation is essential for their photosynthesis process for crop growing, however, high levels of solar radiation may adversely affect the crop quality. Therefore, a balance between the need for sufficient solar radiation for plant grows and the need for electricity is important to maintain. Many greenhouses are built with curved rooftops of convex shapes and flat-plate photovoltaic (PV) modules are deployed on the rooftops. The present study proposes using flexible PV modules adhering to the curvature of the roof. The incident solar radiation on a curved surface is not uniformly distributed along the surface, therefore the density of the solar irradiation attains higher levels at regions where the PV modules may be deployed to generate greater amounts of electric power. The present study determines the density variation of the solar irradiation, in $\mathrm{Wh} / \mathrm{m}^{2}$, (direct beam, diffuse and global) along the curvature of the convex surface of the greenhouse, and proposes the location of the PV modules to be deployed on the roof to obtain desired levels of solar radiation needed for designing the PV systems. North-south and east-west greenhouse orientations are considered.
\end{abstract}

Keywords: photovoltaic greenhouse; convex rooftop; solar radiation distribution; flexible PV modules

\section{Introduction}

The popularity of the cultivation of vegetables and fruits in greenhouses is recently growing worldwide. A photovoltaic (PV) greenhouse may be considered an example of Building Integrated Photovoltaic (BIPV) system in the sense that BIPV simultaneously provides both shading for reducing cooling loads and for electric power generation. However, shading by the PV modules placed on a greenhouse roof may introduce concerns about the negative impact of shading on crop yield and fruit quality, depending on the greenhouse environmental location. The difference between BIPV and PV on greenhouses is the amount of generated electricity. The purpose of BIPV on rooftops is to fully utilize the roof area for electric power generation, whereas integrating a PV module on the roof of a greenhouse is to generate sufficient electricity mainly for environmental control of the inside air temperature. Solar radiation is essential for the photosynthesis process for crop growing, however, high levels of solar radiation may cause accumulation of excessive heat inside the greenhouse adversely affecting the crop quality. Therefore, one has to seek a balance between the need for sufficient light for plant growth and the need for electricity for controlling the environment inside the greenhouse. For this reason, research on photovoltaic greenhouses concentrates on the percentage of shading by the PV modules on the roof that is compatible with each type of crop. The amount of shading by the PV modules inside the greenhouse depends on the site latitude, season, time of the day, inclination of the PV modules, their arrangement on the roof, and the percentage of roof coverage by the PV modules. The shape and orientation of the greenhouse are factors for the air temperature inside the greenhouse. The literature on PV greenhouses is extensive. Reference [1] reviews the literature for the application 
of selective shading on crops by PV modules deployed on greenhouse roofs. In [2], the authors review factors influencing the microclimate of the greenhouse. Variable shading by rotating the PV modules on the greenhouse roof is discussed in [3]. The study in [4] concentrates on the most suitable shape and orientation of a greenhouse structure on the basis of the global solar radiation availability and its subsequent effect on the air temperature inside the greenhouse. Detecting the shading effect of mobile PV modules on the growth of some flowers is in [5]. The study in [6] investigates the effect of PV shading on Welsh onion growth. Two arrangements of the PV module on the greenhouse roof were tested: straight-line and checkboard. The checkboard formation allowed intermittent shadow casting thus resulting in a better sunlight distribution in the greenhouse. The work in [7] assessed the sunlight energy in an east-west oriented Gothic arch greenhouse equipped with PV modules. The light distribution inside the greenhouse was measured in [8] by pyranometers to verify the solar calculation. The shading variation in [9] was analyzed inside a prototype greenhouse with PV modules arranged in checkerboard. Tomatoes and leaves grown in the presence of a shade mesh to reduce the amount of sunlight were studied in [10]. The influence of whitening a greenhouse roof on the microclimate and yield of tomato crops was analyzed in [11].

Environmental control of the inside air temperature may be achieved by forced or by natural ventilation. A balance is needed between removing excess heat and keeping the correct amount of relative humidity inside the greenhouse. Reference [12] analyzes two greenhouse evaporation cooling systems. Reference [13] studied airflow patterns in greenhouses under natural ventilation conditions in a Mediterranean environment. In Reference [14], different natural ventilation models have been analyzed in a multi-span greenhouse. The effect of the ventilator configuration on the flow pattern of neighboring three-span Mediterranean greenhouses with an obstacle to airflow was investigated in [15].

In References [1-9], flat-plate PV modules are used for the PV systems. The majority of the roofs of greenhouses are constructed with convex surfaces, and, therefore, it is of technical advantage to use flexible PV modules deployed along the curvature of the convex surface. The study of "curved photovoltaic collectors-convex surface" in [16] just fits well into the application of PV modules on rooftops of greenhouses. This study showed, for the first time, that the incident solar radiation on a convex surface is non-uniform. Non-uniform incident solar radiation on PV collectors is a disadvantage for the purpose of generating electric power, however, the feature of non-uniform radiation may be utilized in the design of PV systems on greenhouse rooftops. Non-uniform incident solar radiation on a surface results in non-uniform density of the solar irradiation (in $\mathrm{Wh} / \mathrm{m}^{2}$ ), and thus may point to the location on the roof for deploying the PV modules where the incident solar radiation is high. The size of the PV array may then be smaller, thus reducing shading, or increasing the amount of electric energy generation, whatever the need is. The distribution of the incident solar radiation on greenhouse rooftops of convex shapes was not published, as far as we know. The aim of the present study is to determine the variation of the incident solar irradiation density, (direct beam, diffuse and global), along the curvature of the convex surface of the greenhouse, and to indicate the disposition of the PV modules' deployment on the roof to obtain desired levels of solar radiation enabling, thereafter, the design of PV systems. Many aspects are involved in the design of greenhouses with PV modules-; among them are: controlling the inside air temperature, the amount and profile of electricity generation, the size of the PV array, the level of solar irradiance and the spectrum for crops growth, and the amount of required shading. The purpose of the present study is to focus on an additional aspect pertaining to convex surfaces, meaning the distribution of the incident solar radiation along the curvature surface and consequently, pointing to the desired location of the PV array on the rooftop. 


\section{Materials and Methods}

A convex surface is shown in Figure 1, pointing due south. The surface may be described mathematically by a function of the form:

$$
f_{c}(y)=-a y^{2}+b, a>0, b>0
$$

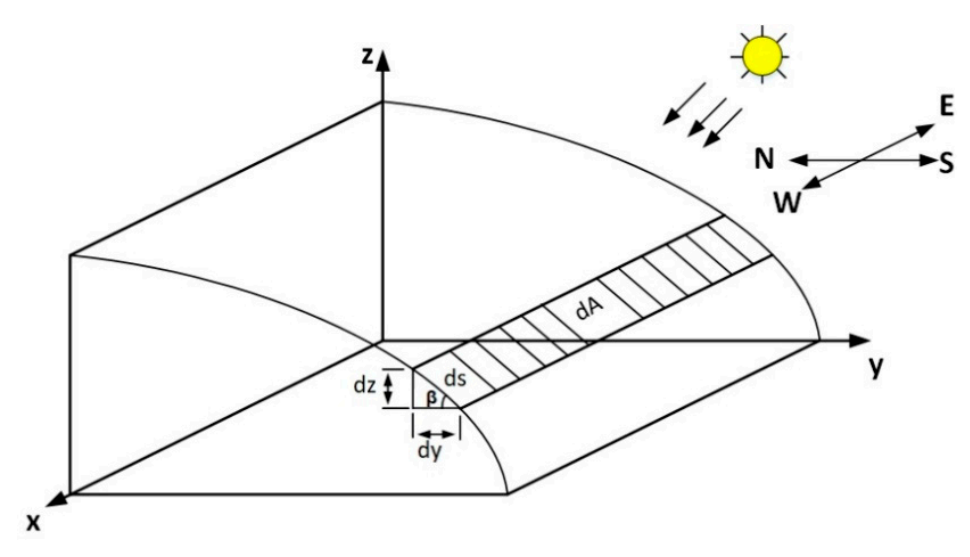

Figure 1. Elementary area $d A$ of a convex surface.

For a small $d s, d s=\left[(d z)^{2}+(d y)^{2}\right]^{1 / 2}=\left[1+(d z / d y)^{2}\right]^{1 / 2} d y$, or

$$
d s=\left\{1+\left[f_{c}^{\prime}(y)\right]^{2}\right\}^{1 / 2} d y
$$

where $f_{c}^{\prime}(y)$ is the derivative of $f_{c}(y)$.

From Figure 1 we get:

$$
\begin{aligned}
& \sin \beta(y)=d z / d s=\frac{\left|f_{c}^{\prime}(y)\right|}{\left\{1+\left[f_{c}^{\prime}(y)\right]^{2}\right\}^{1 / 2}}, \\
& \cos \beta(y)=d y / d s=\frac{1}{\left\{1+\left[f_{c}^{\prime}(y)\right]^{2}\right\}^{1 / 2}},
\end{aligned}
$$

The derivative $f_{c}^{\prime}(y)$ of Equation (1) is:

$$
f_{\mathcal{c}}^{\prime}(y)=-2 a y
$$

Equations (3)-(5) indicate that the local inclination angle $\beta$ varies along the surface.

\subsection{North-South Oriented Greenhouse}

\subsubsection{Direct Beam Incident Radiation—South Side}

The direct beam radiation, in Watt, on an elementary area $d A$ of a collector (see Figure 1) is given by:

$$
d P_{b, A}=G_{b} \cdot \cos \theta \cdot d A
$$

where:

$G_{b}$ is the direct beam irradiance in $\mathrm{W} / \mathrm{m}^{2}$ normal to the solar rays

The elementary area is $d A=L \cdot d s$ and with Equation (2) we have:

$$
d A=L \cdot\left\{1+\left[f_{c}^{\prime}(y)\right]^{2}\right\}^{1 / 2} d y
$$


The sun angles involved in solar calculations are indicated in Figure 2, where $\alpha$-sun elevation angle, $\gamma_{s}$-sun azimuth angle, $\theta$-angle of the solar rays normal to the collector surface and $\beta$-inclination angle of the surface.

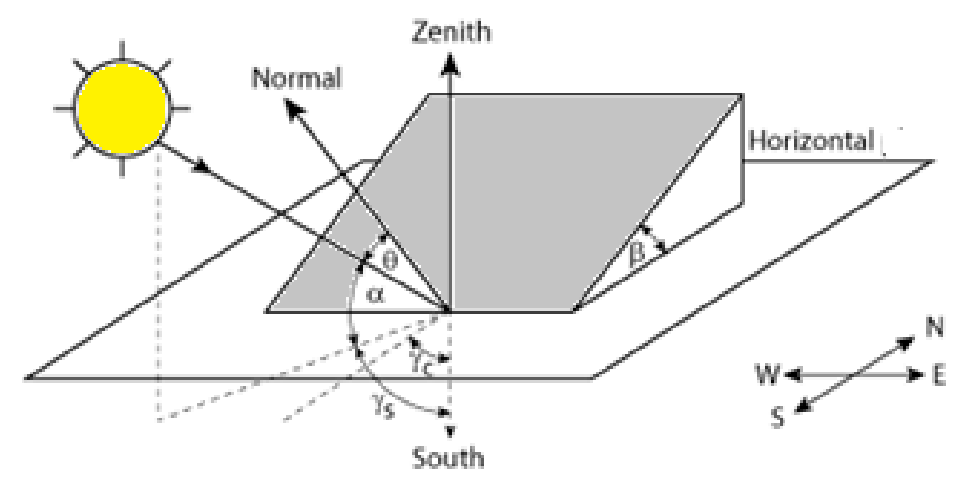

Figure 2. Angles involved in solar calculations.

The sun elevation angle is given by:

$$
\sin \alpha=\sin \phi \sin \delta+\cos \phi \cos \delta \cos \omega
$$

where $\phi$-site latitude and $\omega$-solar angle ( $\omega=0$ noon, $\omega<0$ morning and $\omega>0$ afternoon).

The solar incident angle $\theta$ is given by:

$$
\cos \theta=\cos \beta(y) \sin \alpha+\sin \beta(y) \cos \alpha \cos \gamma_{s}
$$

Substituting Equations (7) and (9) into Equation (6), we obtain the local beam radiation, in Watt, as a function of $y$ along the collector:

$$
d P_{b, A}=G_{b} \cdot L\left[\sin a+f_{c}^{\prime}(y) \cdot \cos a \cos \gamma_{s}\right] d y .
$$

i.e., Equation (10) reveals that the direct beam incident solar radiation on a convex surface is non-uniform and varies along the surface.

A convex rooftop surface of a greenhouse is shown in Figure 3. The rooftop dimensions are:

$$
D=4.0 \mathrm{~m}, H=1.56 \mathrm{~m}, L=21.0 \mathrm{~m}
$$

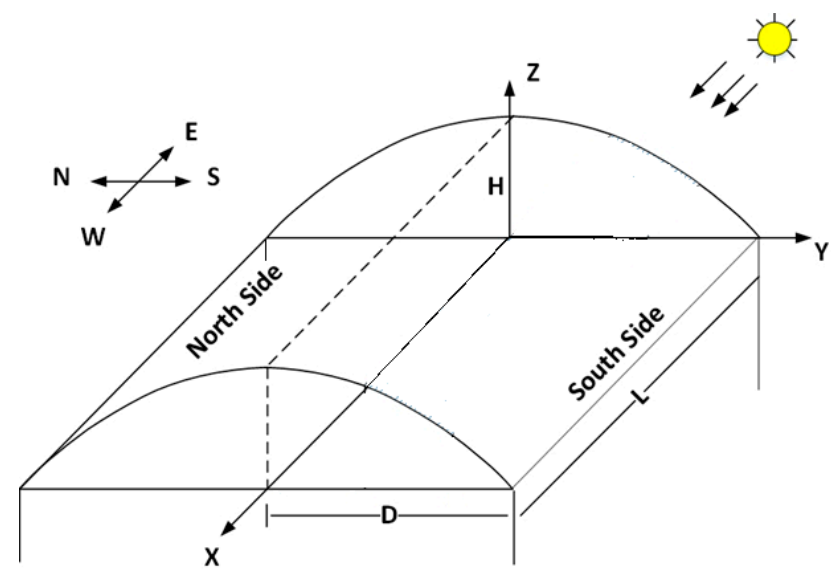

Figure 3. Greenhouse roof. 
Based on the rooftop dimensions, the convex surface may be expressed in the form (see Equation (1)):

$$
f_{c}(y)=-a y^{2}+b=-0.0975 y^{2}+1.56, f_{\mathcal{c}}^{\prime}(y)=-0.195 y
$$

The analysis of the solar radiation of the greenhouse roof is given in the following sections.

(1) Variation of the inclination $\beta$

The variation of the inclination angle along the convex surface is depicted in Figure 4, see Equation (4).

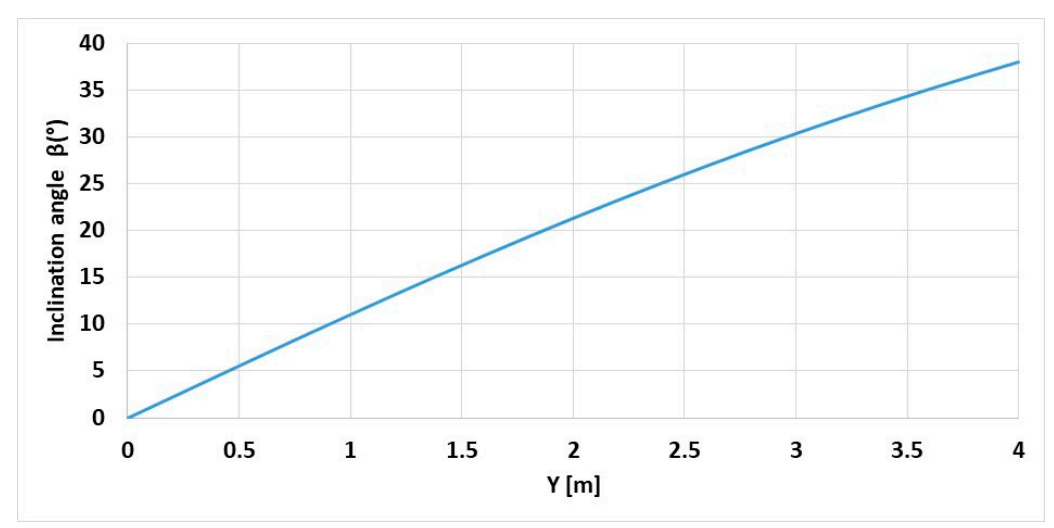

Figure 4. Variation of inclination angle $\beta$ along collector surface.

(2) Direct beam incident radiation-south side of rooftop

The direct beam radiation in Watt between $y_{1}$ and $y_{2}$ is given by, see Equation (10):

$$
P_{b}=G_{b} \times L \int_{y_{1}}^{y_{2}}\left[\sin \alpha+\cos \alpha \cos \gamma_{s} \cdot f_{c}^{\prime}(y)\right] d y
$$

Denoting:

$$
\Delta y=y_{2}-y_{1}
$$

For an increment $\Delta y=y_{2}-y_{1}$, the direct bean radiation is given by, see Equation (11):

$$
\begin{aligned}
& P_{b}=G_{b} \times L\left\{\sin \alpha\left(y_{2}-y_{1}\right)+\cos \alpha \cos \gamma_{s} \mid \int_{y_{1}}^{y_{2}}(-0.195 y d y \mid\}\right. \\
& =G_{b} \times L\left\{\sin \alpha\left(y_{2}-y_{1}\right)+\cos \alpha \cos \gamma_{s} \times\left[0.0975\left(y_{2}^{2}-y_{1}^{2}\right]\right\} .\right.
\end{aligned}
$$

With Equation (13) and the expression in Equation (14), we may write:

$$
y_{2}^{2}-y_{1}^{2}=\left(y_{2}-y_{1}\right)\left(y_{2}+y_{1}\right)=\Delta y\left(y_{2}+y_{2}-\Delta y\right)=\Delta y\left(2 y_{2}-\Delta y\right),
$$

Obtaining the direct beam radiation on an increment $\Delta y$ as function of $y_{2}$ :

$$
P_{b}=G_{b} \times L\left\{\Delta y \sin \alpha+\cos \alpha \cos \gamma_{s} \times\left[0.0975 \cdot \Delta y \cdot\left(2 y_{2}-\Delta y\right]\right\}\right.
$$

(3) Arc length

The incremental arc length is given in Equation (2):

$$
\widehat{\operatorname{arc}}=\int_{y_{1}}^{y_{2}}\left\{1+\left[f_{c}^{\prime}(y)\right]^{2}\right\}^{1 / 2} d y
$$


Using Equation (11) we obtain:

$$
\widehat{\Delta a r c}=\int_{y_{1}}^{y_{2}}\left\{1+\left[f_{c}^{\prime}(y)\right]^{2}\right\}^{1 / 2} d y=\int_{y_{1}}^{y_{2}}\left\{1+\left(0.038025 y^{2}\right)\right\}^{1 / 2} d y
$$

where $c=0.038025$.

Denoting the above integral by $\int_{y_{1}}^{y_{2}}\left(1+c y^{2}\right)^{1 / 2} d y$, the solution is

$$
\int\left(1+c y^{2}\right)^{1 / 2} d y=0.5\left\{y\left(1+c y^{2}\right)^{1 / 2}+\frac{\sinh ^{-1}\left[y c^{1 / 2}\right]}{c^{1 / 2}}\right\}
$$

Thus obtaining for the arc length:

$$
\begin{gathered}
\widehat{\Delta \operatorname{arc}}=\int_{y_{1}}^{y_{2}}\left\{1+\left[f_{c}^{\prime}(y)\right]^{2}\right\}^{1 / 2} d y \\
=\left\{0.5\left(y_{2}\left[1+c y_{2}^{2}\right]^{1 / 2}+\frac{\sinh ^{-1}\left(y_{2} c^{1 / 2}\right)}{c^{1 / 2}}-\left(y_{2}-\Delta y\right)\left[1+c\left(y_{2}-\Delta y\right)^{2}\right]^{1 / 2}-\frac{\sinh ^{-1}\left[\left(y_{2}-\Delta y\right) c^{1 / 2}\right]}{c^{1 / 2}}\right\}\right.
\end{gathered}
$$

The interest is in the variation of the density of the direct beam incident irradiation, in $\mathrm{W} / \mathrm{m}^{2}$, along the convex surface, therefore the radiation in Equation (16) is divided by the area $[L \times \Delta \widehat{a r c}]$. The arc length varies along the surface curvature. The variation of $\Delta \widetilde{a r c}$ length for each $\Delta y$ as a function of $y_{2}$ is shown in Figure 5. For example, at $y=4$, the arc length is $0.251 \mathrm{~m}$ for $\Delta y=0.200 \mathrm{~m}$.

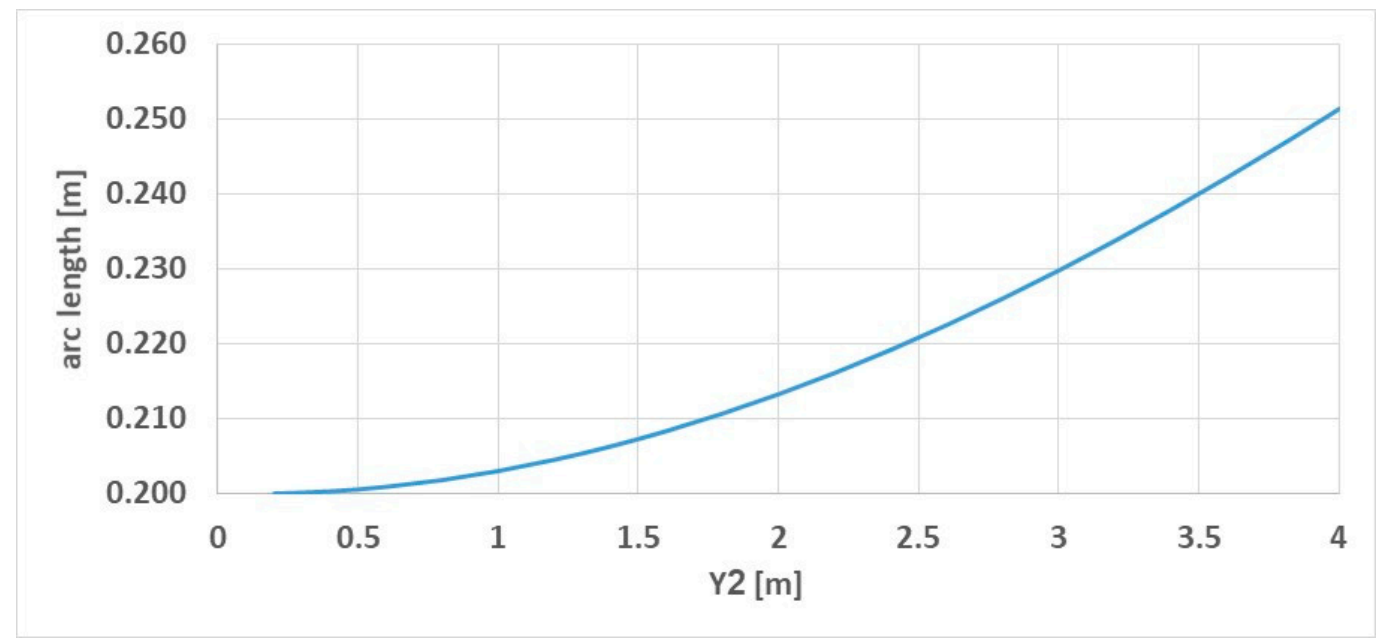

Figure 5. Variation of $\triangle \widehat{a r c}$ length.

The direct beam incident irradiation on the south side consists of two parts [16]: the direct beam irradiation on the south side pointing towards the sun, and the direct beam irradiation on the upper part of the south side when the sun is pointing towards the north side. The density variation of the yearly incident energy of the direct beam, in $\mathrm{kWh} / \mathrm{m}^{2}$, is depicted in Figure 6 calculated by Equations (16) and (19) at latitude $32^{\circ} \mathrm{N}$ (center of Israel), using hourly solar radiation data. The highest energy density on the south side is obtained at a distance about $2.5 \mathrm{~m}$ from the center of the greenhouse.

\subsubsection{Diffuse Irradiation}

The diffuse radiation is given in [16] by:

$$
P_{d}=0.5 G_{d h} \times L \times \int_{y_{1}}^{y_{2}}\left(\left\{1+\left[f_{\mathcal{c}}^{\prime}(y)\right]^{2}\right\}^{1 / 2}+1\right) d y
$$


Obtaining (see Equation (17)),

$$
\begin{gathered}
P_{d}=0.5 G_{d h} \times L \times \int_{y_{1}}^{y_{2}}\left\{\left(1+\left[f_{c}^{\prime}(y)\right]^{2}\right)^{1 / 2}+1\right\} d y \\
=0.5 G_{d h} \times L \\
\times\left\{0.5\left(y_{2}\left[1+c y_{2}^{2}\right]^{1 / 2}+\frac{\sinh ^{-1}\left(y_{2} c^{1 / 2}\right)}{c^{1 / 2}}-\left(y_{2}-\Delta y\right)\left[1+c\left(y_{2}-\Delta y\right)^{2}\right]^{1 / 2}-\frac{\sinh ^{-1}\left[\left(y_{2}-\Delta y\right) c^{1 / 2}\right]}{c^{1 / 2}}+\Delta y\right\}\right.
\end{gathered}
$$

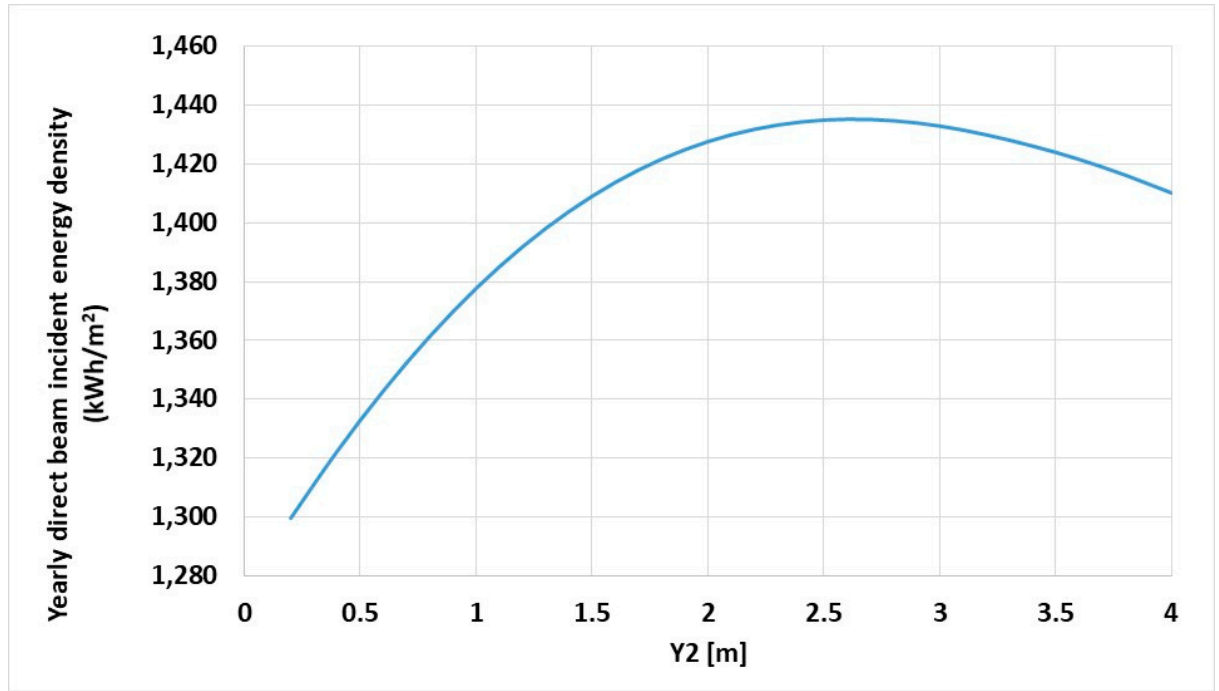

Figure 6. Yearly direct beam incident energy density along the convex surface—south side.

The variation of the diffuse incident energy density along the convex surface is obtained by dividing the diffuse radiation (Equation (20)) by the area $[L \times \Delta \widetilde{a r c}]$, see Figure 7 .

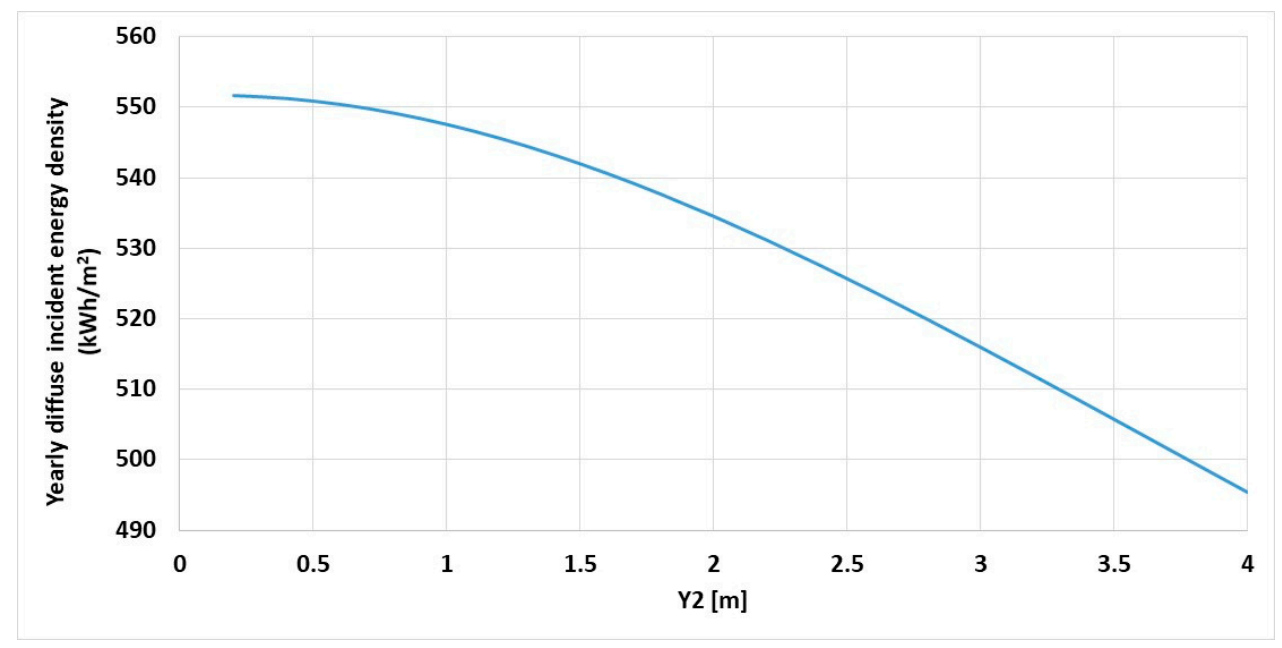

Figure 7. Yearly diffuse incident energy density along the convex surface—south side.

The yearly global incident energy density on the south side of the greenhouse roof is the sum of the direct beam and the diffuse components, see Figure 8 . For a distance of $2.2 \mathrm{~m}$ from the center of the greenhouse, the optimal inclination angle $\beta$ is $22^{\circ}$, see Figure 4 .

\subsubsection{Solar Radiation on Greenhouse Rooftop-North Side}

As mentioned, the north side of the rooftop receives also solar radiation when the sun is on the south side. Figure 9 shows the density of the direct beam incident energy on the north side. 
The diffuse incident radiation on the north side is the same as for the south side. The yearly global incident energy density on the north side is shown in Figure 10.

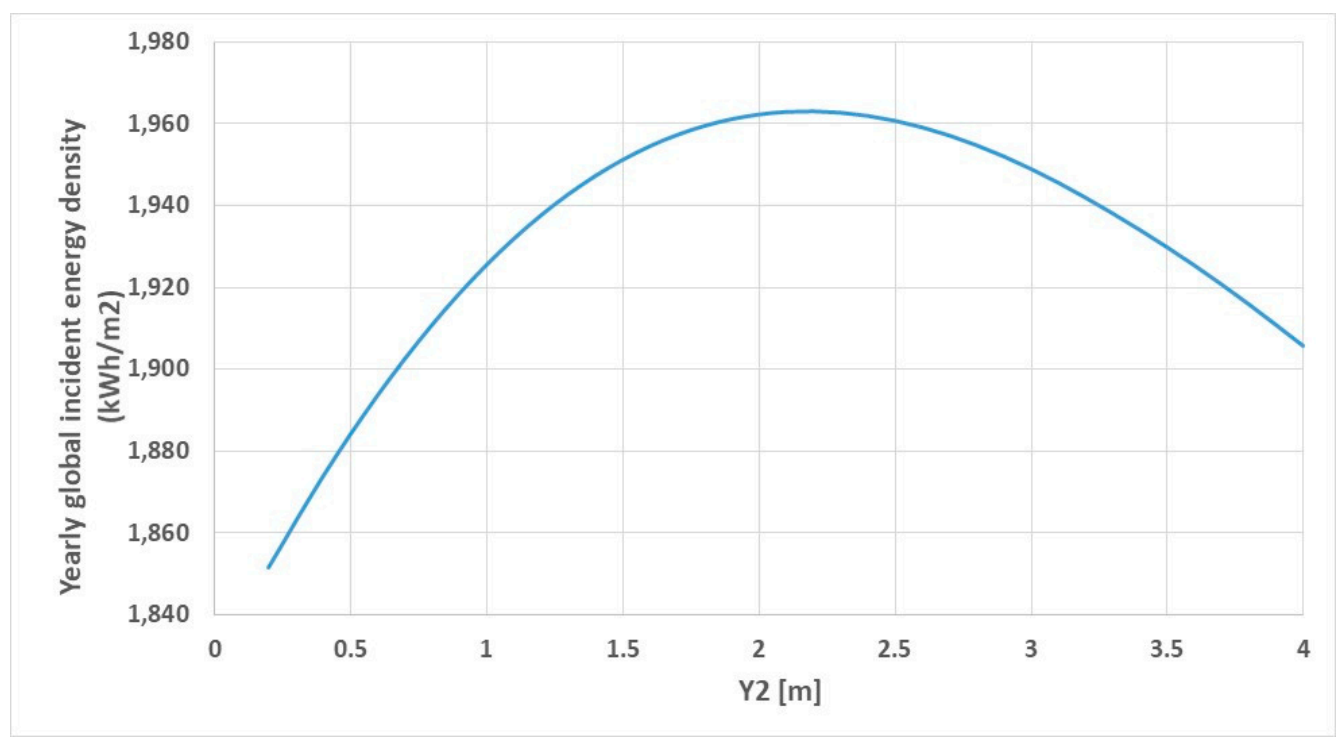

Figure 8. Yearly global incident energy density along the convex surface-south side.

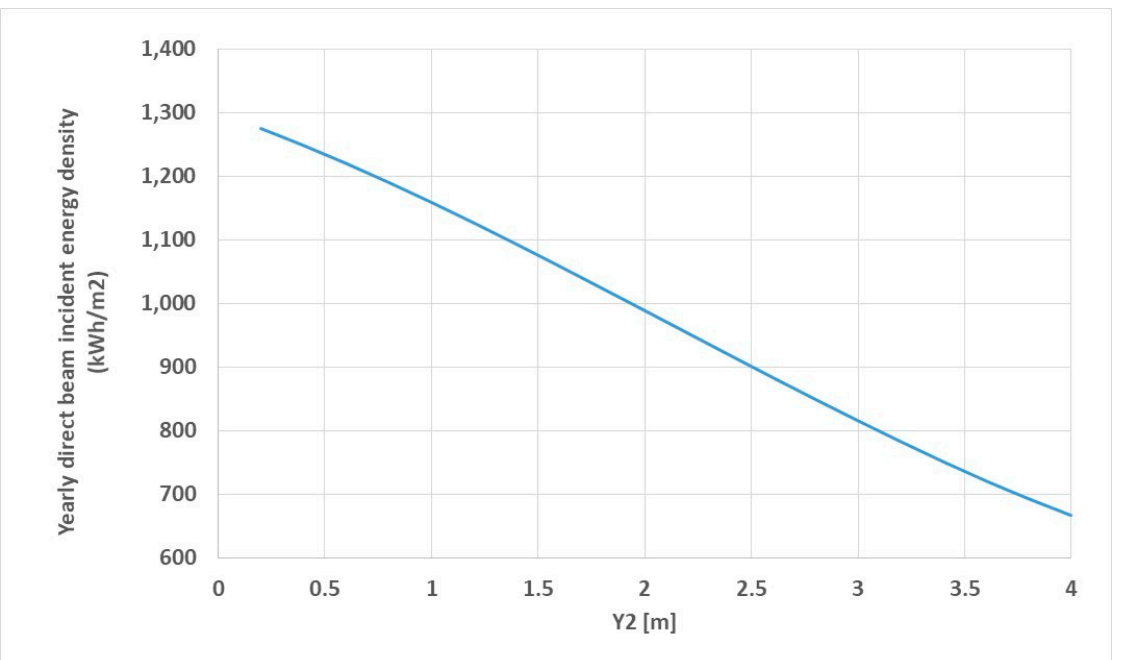

Figure 9. Yearly direct beam incident energy density on the north side.

\subsection{East-West Oriented Greenhouse}

The incident solar radiation on an east-west oriented greenhouse rooftop is assumed to be symmetrical on the east and on the west sides. Figure 11 shows the variation of the direct beam incident energy density on one side of the rooftop. The variation of the diffuse energy density is the same as in Figure 7. The yearly global incident energy density on each side of the greenhouse rooftop is shown in Figure 12. 


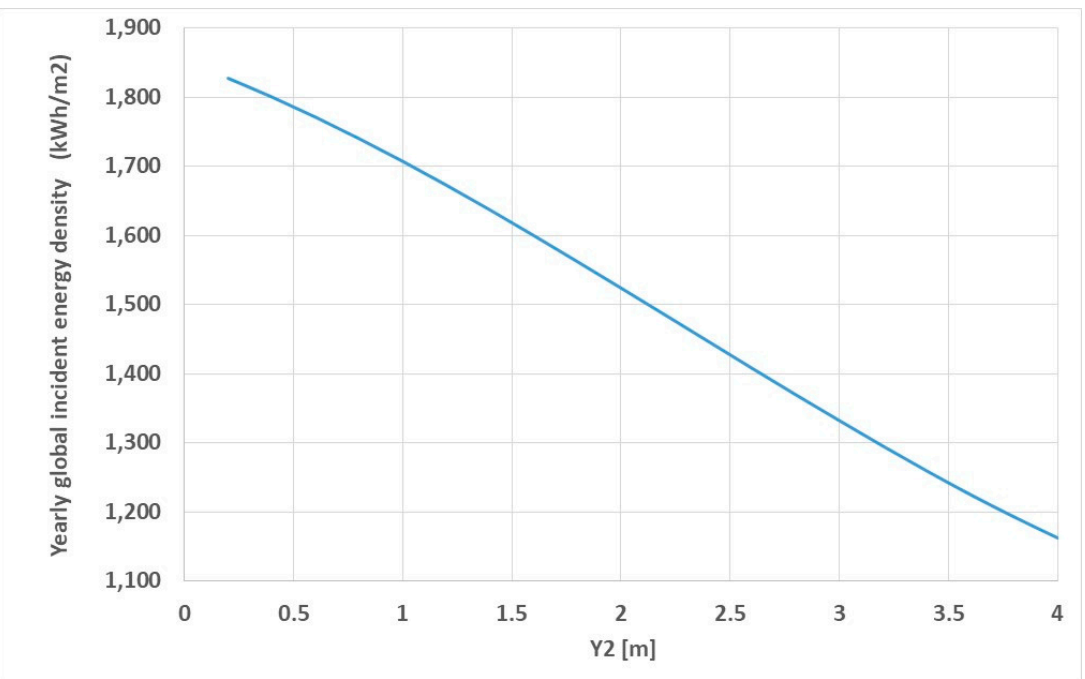

Figure 10. Yearly global incident energy density on the north side.

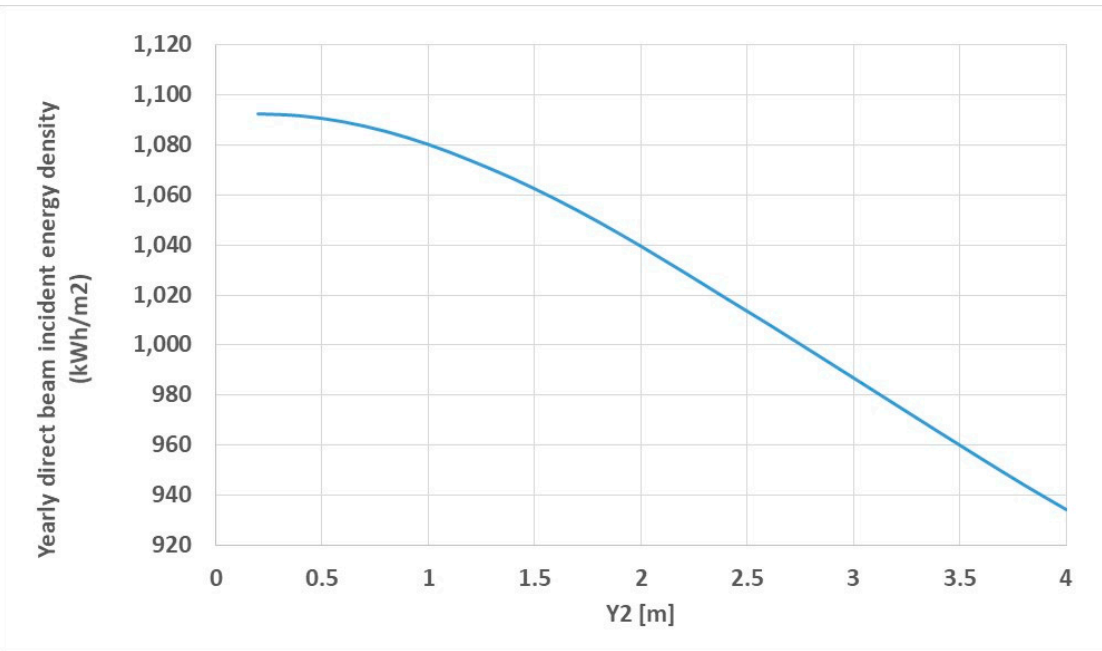

Figure 11. Yearly direct beam incident energy density on east or west side.

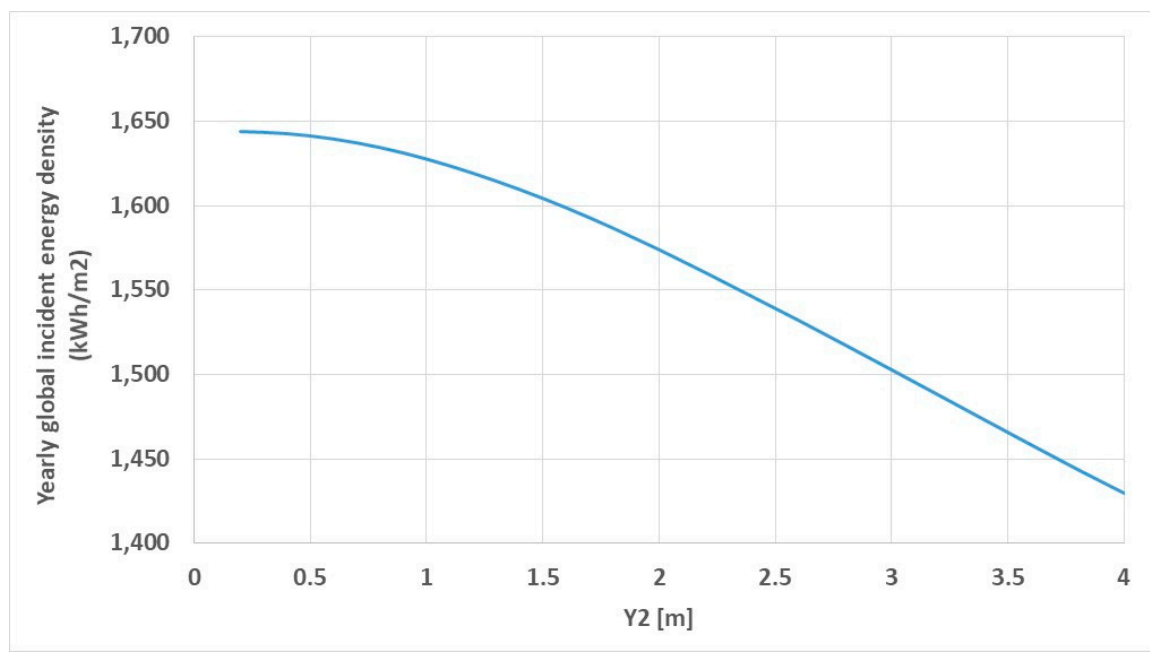

Figure 12. Yearly global incident energy density on east or west side. 


\section{Monthly Incident Irradiation on Greenhouse Rooftop}

The variation of the monthly incident global solar irradiation on the different sides of the rooftop of the greenhouse may be of interest for controlling the inside air temperature for crop growing. The monthly incident solar energy on the north, south and east/west sides of the greenhouse rooftop is depicted in Figure 13. The figure shows appreciable differences in winter times.

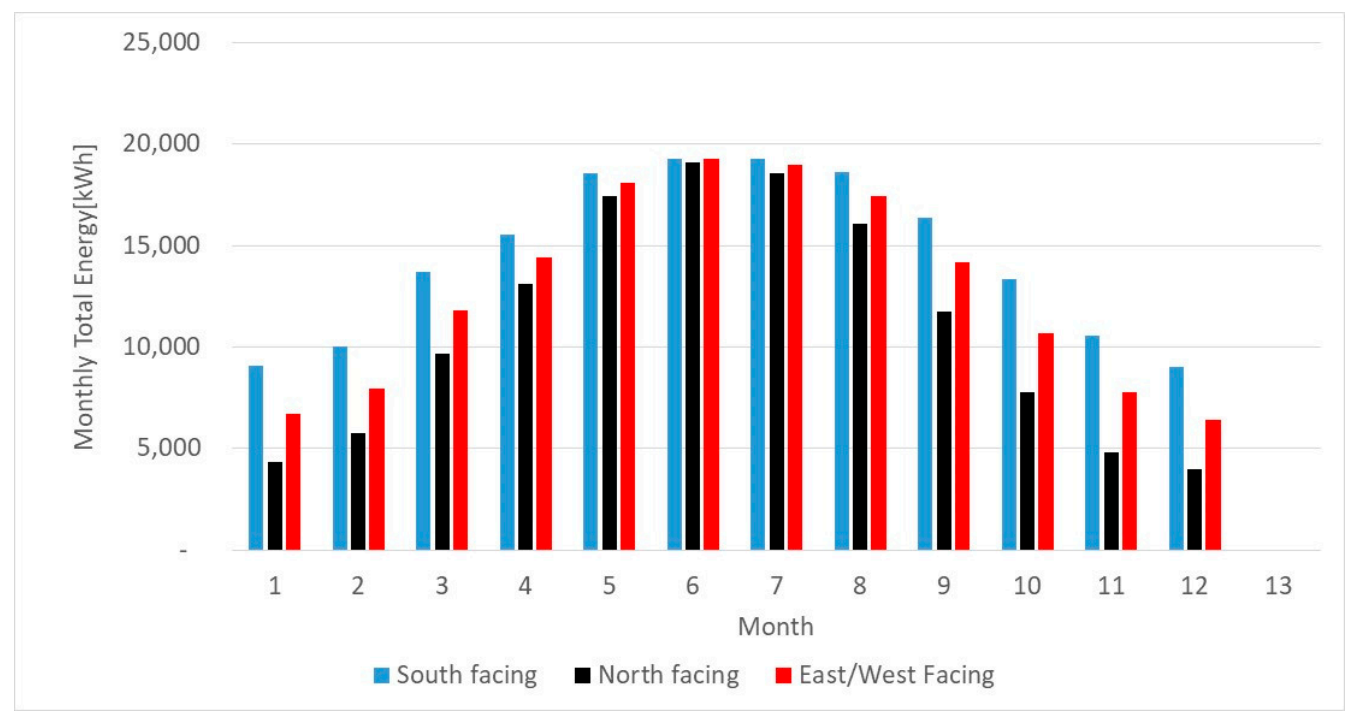

Figure 13. Monthly incident global irradiation on different sides on a greenhouse rooftop.

\section{Deployment of PV Modules on Greenhouse Rooftops}

The deployment of PV modules on the convex rooftop may take place in a variety of options according to the available solar radiation needed for crops growing and the required amount of electricity generation. In this section, the deployment of lightweight flexible PV modules on the rooftop is proposed for north-south and east-west oriented greenhouses. To obtain maximum electric output energy, the PV module are placed where the density of the incident energy is the highest. According to Figure 8 , it is suggested, for example, to place the modules between $D=1.5 \mathrm{~m}$ and $D=3.0 \mathrm{~m}$ on the south side of the roof for north-south oriented greenhouse, see Figure 14. A yearly global incident energy of $67,533 \mathrm{kWh}$ is obtained on the PV modules. Another suggestion may be using sliding PV modules covering part of the fixed-mounted PV modules beneath, see Figure 15, thus reducing the amount of shading cast by the sliding modules. In both arrangements, the north side is fully exposed to the sun rays. The yearly global incident energy on the north side is substantial 136,505 kWh compared to $177,485 \mathrm{kWh}$ on the south side.

An east-west oriented greenhouse rooftop is depicted in Figure 16. The PV modules are deployed on the top of the greenhouse where the incident global energy is the highest, see Figure 12. A yearly incident global energy 58,026 kWh is obtained on the PV modules with the same geometrical size of PV modules as in Figure 14 for which $67,533 \mathrm{kWh}$ is obtained for comparison. The yearly global incident energy on the east/west sides of the rooftop is $158,547 \mathrm{kWh}$ compare to $177,485 \mathrm{kWh}$ on the south side. 


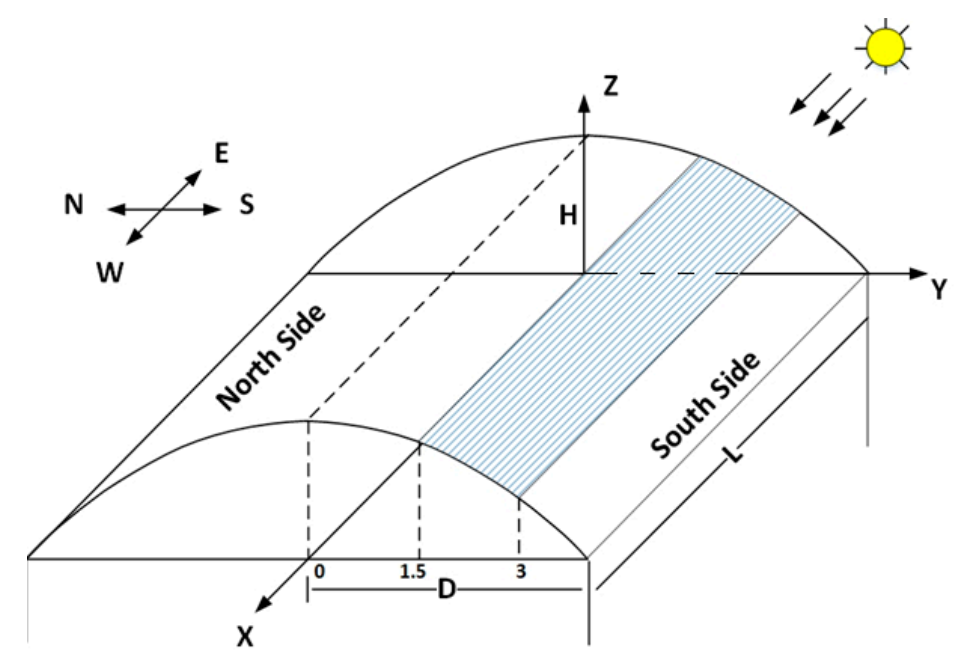

Figure 14. Deployment of PV modules on south side of rooftop.

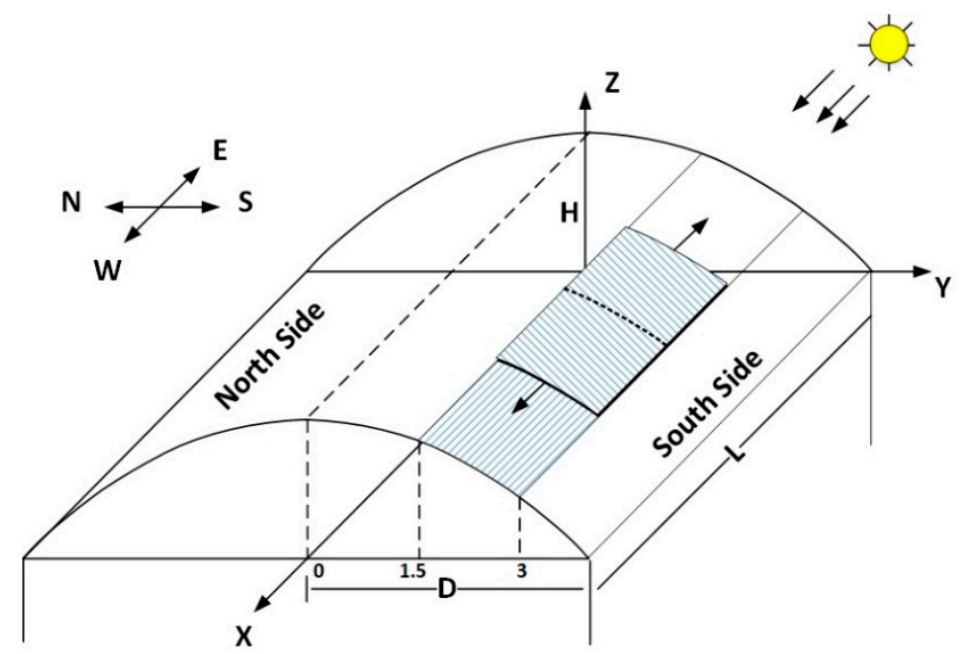

Figure 15. Sliding PV modules of rooftop.

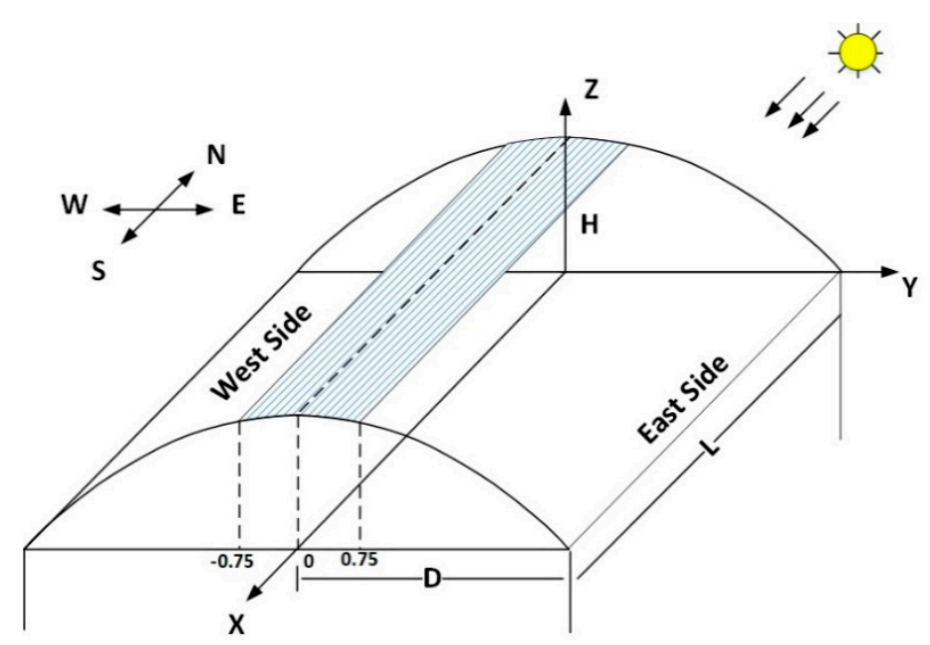

Figure 16. Deployment of PV modules on east-west sides of a rooftop.

\section{Discussion}

The purpose of photovoltaic greenhouses is to grow crops, and at the same time, to generate electricity, mainly for controlling the air temperature inside the greenhouse. These two objectives 
may be in conflict. On one hand, solar radiation is essential for the photosynthesis process for crop growing, on the other hand, PV modules may cast shadows inside the greenhouse thus blocking light to the crops. As the size of the PV module increases, the area of shadow under the module also increases. Looking from another point of view, high levels of solar radiation may cause excessive heat accumulation inside the greenhouse affecting negatively the crop quality. The blocking of some light entering the greenhouse by placing PV module on the roof may mitigate the problem. Using transparent, movable or rotating PV modules was proposed by researches to reduce shading. The amount of allowable shading may vary according to the plant species, geography, meteorology, season and greenhouse parameters. Therefore, a balance is needed between the amount of electricity generation and allowable shading. Environmental control of the inside air temperature in the greenhouse may be achieved my forced or by natural ventilation, for example, by evaporation cooling systems and or by ventilation through windows on the top. Employing natural cooling may reduce the required size of the PV modules. Subsequently, the design of the photovoltaic greenhouse must be individually tailored for each need and location. The present study determines the density variation of the incident solar energy along the curvature of the convex surface of greenhouses, and proposes the location of PV modules deployment on the roof to obtain maximum electricity generation for minimum PV array size. The methodology may be applied to a variety of convex curvatures of greenhouse rooftops.

\section{Conclusions}

Many greenhouses are built with curved rooftops of convex shapes. The present study proposes using flexible PV modules adhering to the curvature of the roof. The incident solar radiation on a curved surface is non-uniform distributed along the surface, therefore the density of the incident solar energy attains higher levels at a region where the PV modules may be deployed to generate higher amounts of electric power. The present study determines, for the first time, the variation of the direct beam, diffuse and global energy density, in $\mathrm{Wh} / \mathrm{m}^{2}$, along a curvature of a convex surface of a greenhouse rooftop, and proposes the location of the PV modules to be deployed on the roof to obtain maximum generated electricity. North-south and east-west greenhouses orientations were studied. For the same PV array size, more energy is generated for north-south oriented greenhouse.

Author Contributions: J.A.: Methodology, A.A.: Software. Both authors have read and agreed to the published version of the manuscript.

Funding: This research received no external funding.

Conflicts of Interest: The authors declare no conflict of interests.

\section{References}

1. Aroca-Delgado, R.; Perez-Alonso, J.; Callejon-Ferre, A.J.; Velazquez-Marti, B. Compatibility between crops and solar panels: An overview from shading systems. Sustainability 2010, 10, 743. [CrossRef]

2. Li, G.; Tang, L.; Zhang, X.; Dong, J.; Xiao, M. Factors affecting greenhouse microclimate and its regulating' techniques: A review. In Proceedings of the 8th International Conference on Environment Science and Engineering, (ICESE 2018), Barcelona, Spain, 11-13 March 2018. [CrossRef]

3. Moretti, S.; Murucci, A. A photovoltaic greenhouse with variable shading for the optimization of agricultural and energy production. Energies 2019, 12, 2589. [CrossRef]

4. Sethi, V.P. On the selection of shape and orientation of a greenhouse: Thermal modeling and experimental validation. Sol. Energy 2009, 83, 21-38. [CrossRef]

5. Calantoni, A.; Monarca, D.; Murucci, A.; Cecchini, M.; Zambon, I.; Di Battista, F.; Maccario, D.; Saporito, M.G.; Beruto, M. Solar radiation distribution inside a greenhouse prototype with photovoltaic mobile plant and effects on flower growth. Sustainability 2018, 10, 855. [CrossRef]

6. Kadowaki, M.; Yono, A.; Ishizu, F.; Tanaka, T.; Noda, S. Effect of greenhouse photovoltaic array on Welsh onion growth. Biosyst. Eng. 2012, 111, 290-297. [CrossRef] 
7. Yono, A.; Kadowaki, M.; Furue, A.; Tamaki, N.; Tanaka, T.; Hiraki, E.; Kato, Y.; Ishizu, F.; Noda, S. Shading and electrical features of a photovoltaic array mounted inside the roof of an east-west oriented greenhouse. Biosyst. Eng. 2010, 106, 367-377. [CrossRef]

8. Cossu, M.; Ledda, L.; Urracci, G.; Sirigu, A.; Cossu, A.; Murgia, L.; Pazzona, A.; Yono, A. An algorithm for the calculation of the light distribution in photovoltaic greenhouse. Sol. Energy 2017, 141, 38-48. [CrossRef]

9. Marucci, A.; Zambon, I.; Colantoni, A.; Monarca, D. A combination of agriculture and energy purpose: Evaluation of a prototype of photovoltaic greenhouse tunnel. Renew. Sustain. Energy Rev. 2018, 82, 1178-1186. [CrossRef]

10. Abreu, A.C.; Marín, P.; Aguilera-Sáez, L.M.; Tristán, A.I.; Peña, A.; Oliveira, I.; Simões, M.; Valera, D.; Fernández, I. Effect of a Shading Mesh on the Metabolic, Nutritional, and Defense Profiles of Harvested Greenhouse-Grown Organic Tomato Fruits and Leaves Revealed by NMR Metabolomics. Agric. Food Chem. 2019, 67, 12972-12985. [CrossRef] [PubMed]

11. Moreno-Teruel, M.A.; Valera, D.; Molina-Aiz, F.D.; López-Martínez, A.; Peña, A.; Marín, P.; Reyes-Rosas, A. Effects of Cover Whitening Concentrations on the Microclimate and on the Development and Yield of Tomato (Lycopersicon esculentum Mill.) Inside Mediterranean Greenhouses. Agronomy 2020, 10, 237. [CrossRef]

12. Lopez, A.; Valera, D.L.; Molina-Aiz, F.D.; Peña, A. Sonic anemometry to evaluate airflow characteristics and temperature distribution in empty Mediterranean greenhouses quipped with pad-fan and fog systems. Biosyst. Eng. 2012, 113, 334-350. [CrossRef]

13. López, A.; Valera, D.L.; Molina-Aiz, F.D.; Peña, A. Sonic anemometry measurements to determine airflow patterns in multi-tunnel greenhouse. Span. J. Agric. Res. 2012, 10, 631-642. [CrossRef]

14. López-Martínez, A.; Molina-Aiz, F.D.; Valera-Martínez, D.L.; López-Martínez, J.; PeñaFernández, A.; Karlos, E.; Espinoza-Ramos, K.E. Application of Semi-Empirical Ventilation Models in A Mediterranean Greenhouse with Opposing Thermal and Wind Effects. Use of Non-Constant Cd (Pressure Drop Coefficient through the Vents) and Cw (Wind Effect Coefficient). Agronomy 2019, 9, 736. [CrossRef]

15. Espinoza, K.; Lopez, A.; Valera, D.L.; Molina-Aiz, F.D.; Torres, J.A.; Peña, A. Effects of ventilator configuration on the flowpattern of a naturally-ventilated three-span Mediterranean greenhouse. Biosyst. Eng. 2017, 164, 13-30. [CrossRef]

16. Appelbaun, J.; Crutchik, M.; Aronescu, A. Curved photovoltaic collector-convex surface. Sol. Energy 2020, 199, 832-836. [CrossRef] 